\title{
La confusión en un grupo grande virtual
}

\author{
J.M. Sunyer ${ }^{1}$ \\ APAG, Barcelona
}

Reflexiono sobre la experiencia de co-conducción de un grupo grande en formato virtual, los mecanismos de identificación proyectiva e introyectiva que se dieron y las dificultades que aparecieron en él.

Palabras clave: grupo grande, confusión, conducción, identificación proyectiva, identificación introyectiva, función.

I reflect on the experience of co-conducting a large group in virtual format, the projective and introjective identification mechanisms that appeared there and the difficulties that I found in doing my work.

Key Words: Large group, confusion, projective identification, introjective identification, function.

English Title: Confusion in a virtual large group

Cita bibliográfica / Reference citation:

Sunyer, J.M. (2021). La confusión en un grupo grande virtual. Clínica e Investigación Relacional, 15

(1): 169-186. [ISSN 1988-2939] [Recuperado de www.ceir.info ] DOI: 10.21110/19882939.2021.150108

${ }^{1}$ Dr. en Psicología. Psicólogo Clínico. Grupoanalista. Profesor Jubilado de la facultad de psicología de la URL. Patrono de la Fundación OMIE. Miembro del Instituto de grupoanálisis (fundación OMIE), de la Asociación de Psicoterapia Analítica Grupal, y miembro de Honor de la Group Analytic Society International. 


\section{Justificación}

A lo largo de las experiencias profesionales que he tenido desde 1976 (Sunyer, 1996, 1998a, 1998b, 2001) destacan, por su magnitud, los grupos grandes. No cabe duda de que son un pozo inagotable de vivencias que llevan a reflexiones en torno a la variedad de fenómenos que se dan en ellos y sobre el ser humano en general.

La mayoría de ellos han sido organizados por la Fundación OMIE en el marco, fundamentalmente, de los cursos de Psicoterapia Analítica Grupal ${ }^{1}$, que se desarrollan en Bilbao, Barcelona y Madrid. Se dan en un contexto formativo de manera similar a las que se dan en otros lugares, tanto en nuestro país como en el resto del mundo, en especial en los Institutos que forman parte de la red europea de Institutos formativos en Grupoanálisis (EGATIN).

La oportunidad más reciente que reactivó este trabajo, tuvo lugar a primeros de septiembre de este año 2020, en el marco del 1er Congreso virtual de la Group Analytic Society International. Cada tres años organiza un encuentro. Éste debía celebrarse en Barcelona. Su lema fue «Las lenguas de los Grupos: el poder de incluir y excluir». Sin embargo, la pandemia obligó a reconsiderarlo y a transformar su formato en virtual. Tal certamen, como es habitual, no deja de ser un espacio de encuentros varios, con diversos formatos grupales (vivenciales y conceptuales) entre los que encontramos los grupos grandes.

Quizás convenga enmarcar la situación de la que hablo. A los simposios de esta asociación suelen asistir entre 300 y 500 profesionales de la psicología y psiquiatría formados en esta corriente de pensamiento y procedentes de todo el mundo. Todos los encuentros se organizan bajo criterios grupoanalíticos combinando la asistencia a conferencias y ponencias con la participación activa en espacios grupales, pequeños, medianos o grandes. Lo que los convierte en un espacio en los que la experiencia personal se enriquece intelectual y vivencialmente. En el grupo grande subyace la filosofía de que ahí van a poderse hablar cualquiera de los aspectos que tengan que ver con los emergentes que han aparecido en los grupos pequeños - de hasta ocho miembros-, en las conferencias o presentación de trabajos, o de las dificultades de índole administrativa que sostienen el propio proyecto, o elementos sociales que emerjan del congreso o lo condicionen, siguiendo el principio grupoanalítico (y psicoanalítico) de una conversación libre entre todos los participantes.

Fueron tres encuentros en formato de grupo grande, conducidos por Sue Einhorn, Elisabeth Rohr y yo mismo, siendo uno de nosotros el «conductor de referencia» si bien los tres coparticipamos al alimón en los tres encuentros. En este trabajo reflexiono sobre su segundo 
encuentro - casi 300 participantes - en el que la confusión señoreó a lo largo de toda la sesión. El encuentro fue virtual, con traducción simultánea al español o al inglés según el hablante.

\section{La escena}

Fueron tres encuentros. En el primero, muchos de los 270 participantes expresaron el placer y la ilusión del reencuentro ya muchos de ellos se conocían previamente. En el tercero mostraron su gratitud y las ganas de volverse a ver. El nudo, como en cualquier acto teatral, se encontró en la segundo.

Para tener una cierta objetividad y ya que por preservar la privacidad no se habían grabado las sesiones, le pedí a dos participantes, que me redactaran unas cinco o seis líneas describiendo lo ocurrido. Sus versiones aparecen tras mi primera descripción.

Se inicia con mi bienvenida por ser el conductor referente en esta ocasión. Al poco, una persona protesta por no haber sido reconocida por una autoridad del Congreso por ser de Palestina; y achacándolo a una actitud discriminatoria por razones ideológicas. Este comentario activó una sucesión encadenada de reproches cruzados entre varios componentes. Incluso le reprocharon a quien había iniciado la protesta de haber elegido un conductor Israelí con el que acabó peleada ;hace tres años! El responsable del congreso que tuvo ese olvido pidió disculpas achacándolo a la propia complejidad del evento y el estrés asociado. Pero los comentarios críticos se mantuvieron, esta vez centrándose en otros compañeros del grupo y siempre sobre la base de discriminar por los aspectos étnicos -no lingüisticos, aunque también-. Alguien comentó que las disculpas que había expresado el director del Congreso suponían un reconocimiento que también había que valorar; pero no fue atendido. La tensión fue incrementándose con alusiones a otras etnias de África también en conflicto o sin reconocimiento, y a problemáticas en otros continentes. Incluso otra persona - no catalana-aludió a los derechos del pueblo catalán a su destino.

Ante esta situación, los conductores intentaron introducir algo de pensamiento incluso aduciendo que quienes estábamos no éramos más que representantes de nosotros mismos y no de ningún territorio o etnia; que envolverse e banderas suponía sustituir la identidad individual por la colectiva en un momento en el que quienes estábamos aquí éramos personas concretas.

Pero estas intervenciones y otras no aplacaron la espiral de reproches, alguno de ellos con matices muy personales. Algunos de los asistentes se mostraban en formato oculto e incluso chateaban entre sí interrumpiendo o distrayendo la atención de los conductores. Para más 
inri, aparecieron dificultades técnicas que hacían más difícil el seguimiento por parte de los traductores; hasta el extremo de que la imagen del conductor principal desapareció de la pantalla lo que llevó a comentarios cargados de mucha angustia. El clima fue calentándose y la sesión acabó de forma súbita al finalizar los 90 minutos y quedar desconectado el sistema.

\section{Observador 1:}

El segundo grupo grande empezó con unas palabras del Director del simposio y presidente de GASI. Dijo que sentía mucho su error en la inauguración del encuentro al no haber mencionado la presencia de Palestinos en él. Esto había sido reclamado por una participante de Palestina en la primera sesión del día anterior. Enseguida empezó una lucha verbal entre Israelies y Palestinos que resultó interminable. A los conductores les era imposible interrumpir o intervenir. Tanto el grupo como los conductores se encontraban en una parálisis crónica sin fin.

Reflexionando esta situación me parece, que este anuncio del presidente provocó un sentimiento de impotencia total en el grupo que no podía ser contenido. Si el presidente comete un error y lo dice, significa que falta una figura con autoridad y, tras ello, empieza una batalla entre los hermanos. Sus palabras eran demasiado en esta situación y el grupo no podría contenerlas. No abrieron un camino para reflexionar su error, y sí el camino para una guerra, entre víctimas y victimarios, pelea que ellos negaron. El ataque era fuerte y mostraba la fuerza devastadora tras todo el conflicto entre Israelíes y Palestinos.

Observador 2:

El GG lo abre el presidente de la GASI disculpándose por no incluir a Palestina en la bienvenida del día anterior...creo que eso ya condiciona mucho la sesión. El grupo está todo el rato en ataque-fuga portavoceado por los israelíes como "opresores» y las palestinas (todas mujeres por cierto) como «pueblo oprimido», aunque los primeros tratan de derivar malestar hacia Inglaterra como el poder establecido en GASI a través del lenguaje. El conductor hace intentos porque nos podamos escuchar y pensar pero es imposible, hay mucha crispación. Trata de introducir el "hablar desde cada uno y no desde la bandera»; pero en ese contexto acaba siendo echar más gasolina al fuego de la confrontación. El GG se torna muy incómodo para muchos de los participantes y tiene su clímax en la agresividad con la que se expresa uno de los israelíes hacia una palestina, es una escena muy desagradable... Al final el conductor lo puede cerrar de la mejor manera posible, pero queda una sensación de que se ha volcado mucha rabia y frustración, ¿quizá también por no haber podido estar juntos presencialmente? O al revés, ¿que por haber sido por zoom han podido participar personas que normalmente no lo hacen porque no se pueden pagar el viaje ni 
alojamiento? ¿Al ser más inclusivo, integrador e igualitario en este sentido a lo mejor ha molestado a algunos?

Como se puede apreciar hay lógicas discrepancias atribuibles a la distancia entre el hecho y su relato escrito días después; o a la confusión del propio grupo.

Voy a centrarme en este segundo tiempo. Intentaré contestar a tres preguntas:

a) ¿cómo entender que profesionales con experiencias en este tipo de grupos entremos con tanta facilidad en un rio de asociaciones que nos empujaban a la confusión?

b) ¿Cómo no daban fruto nuestros intentos por encauzar el pensamiento hacia lo creativo?

c) ¿Por qué un grupo grande tiende o incluye la confusión en su dinámica y cómo se introduce y se sale de ella?

\section{Grupo grande, definición}

Foulkes (1975) en la aportación más clara que conozco al respecto dice:

No se ha debatido mucho sobre el tamaño óptimo (de un grupo). ¿Cuándo se convierte en un grupo grande? ¿En qué momento cambia su carácter? La pregunta es importante si consideramos que no tenemos simplemente un grupo grande y un grupo pequeño, sino que nos movemos en una escala en la que todo esto es un poco relativo. El punto esencial a subrayar es que la cantidad se convierta en calidad (...). El salto que supone pasar de 8 a 30 ó 40 miembros, por no hablar de 100, supone características de grupo muy diferentes (...) Por ejemplo, en grupos mixtos (...) 8 parece ser el número correcto. De 8 ó 9 en adelante hay un cambio considerable en su carácter; aceptemos que ése se mantenga hasta, digamos, las 14 personas. La zona entre 14 y 20 miembros o incluso 25, que yo sepa, no se explora desde este punto de vista (...) una vez que tenemos 30 ó 40 individuos, solo 10 ó 20 pueden marcar la diferencia. El tipo de grupo que tenemos en mente al pensar en grupos grandes está formado, al menos, por 30 personas; pero más probablemente entre 50 y 100 o incluso 120. (1975:51-2)

Es posible que esta referencia es a la que nos hemos acostumbrado, o la que hemos admitido tácitamente. Coincido con él: un grupo formado por hasta diez miembros es un grupo pequeño; hasta la treintena, lo llamaré mediano y, a partir de ese número nos encontramos 
en un grupo grande; teniendo siempre presente que la frontera entre unos y otros es muy difusa. (Sunyer, 2008).

Tal clasificación no es aleatoria. Anzieu (1978), nos dice al respecto que:

varía entre siete y quince, siendo ocho el óptimo para un grupo de psicoterapia, y diez o doce para un grupo de formación. Las razones se basan en una ley que la dialéctica ha enunciado desde hace tiempo: llegado a un cierto umbral, la variación cuantitativa, produce un salto cualitativo (...) el total de relaciones interindividuales posibles entre $n$ individuos se halla por medio de la siguiente fórmula: $n(n-1) / 2 .(1978: 34-5)$

Ello confirma que el número de interrelaciones que se dan aumenta exponencialmente en función del número de participantes. Seguramente ahí anidan las dificultades que emergen en el grupo grande.

Pat de Maré (1991, 2010) al hablar de grupos grandes piensa en aquellos que contienen un número por encima de la veintena; sin embargo, dice que:

en 1987 se decidió en el seminario establecer una sección de grupo grande como parte de la Sociedad Grupo Analítica. Se hizo cada vez más evidente que, dado que los grupos grandes acababan siendo de mediano tamaño y no grandes, debería haber, por lo tanto, dos secciones. Una sección de grupo mediano que está resultando muy activa, y una sección de grupos grade que, hasta la fecha no se ha desarrollado. El grupo grande es todavía un término demasiado general o global. (1997:23)

Quizás por ello puso más acento en lo que sucede en los grupos medianos que en los grandes. Y cuando introdujo el término koinonia - comunión- subrayaba la capacidad de quienes constituyen un grupo de este tamaño, para desarrollar unas relaciones basadas más en la colaboración que en la competición.

No todo el mundo se ciñe a esta idea clasificatoria; que no deja de ser relativa. Tampoco creo que en un grupo pequeño sea más difícil percibir los elementos sociales. Sí, que las dinámicas que se dan en un grupo grande se equiparan mucho a lo que Volkan describe en relación a los grupos sociales. Dice:

«un grupo grande es aquel formado por decenas, o cientos, o miles o millones de individuos muchos de los cuales no se conocerán en la vida, no sabrán de su existencia, a pesar de compartir un sentimiento de semejanza» (2013:29).

Así podríamos considerar a la humanidad como un grupo grande muy fragmentado y con altas tensiones entre los diversos subgrupos - naciones-. Su perspectiva proviene de sus experiencias de mediación entre sociedades, habiendo intervenido en numerosos conflictos 
interétnicos (2004, 2006, 2013a 2013b) poniendo el acento en la identidad y cómo ésta se siente amenazada o manipulada, aunque también constituida a partir de las relaciones que se dan en los contextos grandes. Esto lo vemos también en nuestros grupos grandes.

Al proyecto se le añadió un parámetro novedoso: la Pandemia nos obligó a replantear el simposio y ante la imposibilidad de hacerlo presencialmente nos reinventamos transformándolo en virtual. Eso fue novedad para todos, fundamentalmente por lo que supone trabajar en un grupo grande de casi 300 personas.

En efecto, a partir de marzo del 2020 se comenzaron a utilizar a gran escala diversos programas que permiten agrupar a personas virtualmente -la propia experiencia de grupo grande del 1er Congreso virtual de la GASI fue un ejemplo- pudiéndose constatar los movimientos emocionales que se suscitan. Lo que no deja de ser un campo de interés y reflexión teórica y práctica; con su complejidad y si somos capaces de salir de la parte seductora de los mismos.

Así pues, se convocó a los participantes a participar en tres grupos grandes - función convocante, (Sunyer, 2008) - para comunicarnos, dialogar e intercambiar nuestras experiencias centradas en el aquí y ahora del encuentro; aunque salpicadas por las que cada uno ha tenido o tiene y que proceden de sus entornos grupales.

Llegados aquí, entraré en las tres cuestiones planteadas. Vayamos a por la primera: ¿cómo entender que profesionales con experiencias en este tipo de grupos entremos con tanta facilidad en un rio de asociaciones que todas ellas nos empujaban a la confusión?

\section{La confusión}

Vaya por delante señalar que ser profesionales no nos vacuna ante estados de ansiedad y confusión. En muchos casos provienen más del contexto relacional en el que nos encontramos que de situaciones personales. Y aunque la formación nos de instrumentos y conocimientos, no necesariamente evita que entremos en ellos cuando nos encontramos en aguas revueltas.

En 2001 abordé la confusión en los grupos: esa experiencia emocional, psíquica, por la que la ansiedad ante una situación dada genera o activa señales que afectan a su forma de vivir lo que está viviendo y a la de relacionarse con los demás. El individuo percibe una cierta dificultad para entender lo que oye o está viviendo, y organizar un pensamiento enlazable con el que se da en el contexto. Ello activa pensamientos poco coherentes, muy diversos y poco conectados realmente con la situación en la que se encuentra, dificultades de comprensión, vivencias de no pertenencia y hasta una cierta desrealización que, a su vez, 
incrementan el estado de alarma. La vivencia de soledad y de no reconocimiento por parte de los demás, incrementan las señales de angustia.

Cuando la ansiedad —difícilmente reconocible como tal por lo absurda que se la vive- se eleva, las dificultades inciden en las percepciones de los demás, del lugar en el que está con modificaciones del espacio y tiempo-; le emergen dudas respecto a la intencionalidad de quienes le rodean pudiéndose sentir perseguido por sus ideas o por lo que le dicen. $Y$ aunque en muchos casos el individuo sabe que lo que vive tiene un punto de irracionalidad, no puede evitarlo; ello activa una disociación -lo que se vive, lo que se piensa- que activa la confusión personal y la vivencia de marasmo. No dudo del incremento del malestar personal y de la rabia, enfado y hasta odio que se siente en estas situaciones hacia quienes le rodean; sentimientos que, a la par que se rechazan, se viven.

Estos estados de confusión con desrealización, desorientación temporo-espacial o, incluso, con alteraciones perceptivas, son pasajeros y remiten en breve tiempo. Suelen sorprender (y asustar) más a quienes no están habituados a ellos pudiéndose decir que el neurótico está menos cómodo en los grupos grandes que el psicótico: los sistemas de defensa vital y comunicación que utilizan - y a los que están algo más habituados- les permite capear mejor la situación de confusión que a quienes estamos en el grupo genérico de neuróticos. Cierto que el Yo de una persona no siempre se ve capaz de retomar el equilibrio y apaciguar estas vivencias; en algunos casos muy concretos se ha precisado la ayuda complementaria profesional e, incluso, algo de medicación².

En un grupo grande, todo adquiere una dimensión que sobrepasa las capacidades individuales de elaboración de las percepciones que se tienen. Las informaciones que captamos a través de nuestros sentidos superan las capacidades individuales para procesarlas. Toda adquiere tal volumen e intensidad que no siempre nuestra capacidad mental da abasto con ello. Nuestros mecanismos de comunicación no siempre son capaces de contener la información ansiógena con la que conectan. Lo cognitivo queda desbordado por lo emocional que es quien prima en la interpretación de lo que se percibe. Eso guarda relación con, al menos, dos elementos: el propio grupo y la forma de conducirlo.

\section{El grupo: sala de espejos}

No parece descabellada esta idea de Foulkes (Nitsun, 1996). En realidad, si cada cual es para los demás un objeto en el que se ven reflejadas muchas de sus características personales proyecciones e identificaciones proyectivas mediante-, bien podemos decir que el grupo se asemeja a ese laberinto especular que encontramos en los parques de atracciones. Con las 
distorsiones propias de cada superficie reflectante. La complicación proviene de que son muchas y muy diversas las imágenes que percibimos de nosotros a la vez, y no siempre somos capaces de aunarlas diferenciando la parte proyectada de la propia distorsión del espejo. Así, un comentario despierta tantas respuestas contradictorias entre sí, que sujeto se vive desmembrado afectando a su propia identidad.

Defiendo la idea de que los mecanismos de comunicación psíquica se corresponden a los denominados mecanismos de defensa (Sunyer, 2018). En realidad, todo mecanismo defensivo siempre informa de algo. Por poner un ejemplo, poner una alarma en casa indica del miedo que se tiene ante la posibilidad de que alguien pueda entrar en ella. Lo mismo sucede con nuestros mecanismos defensivos. Advierten o transmiten la idea de que algo está pasando ahí: algo asusta, algo de la identidad se tambalea, o aparecen modificaciones en la permeabilidad de la membrana psíquica.

En una situación de grupo pequeño, estos procesos también están activos; aunque están más contenidos. Sin embargo, el agrandamiento del grupo -mayor número de espejosincrementa los temores y, en consecuencia, esos mecanismos se ponen más en evidencia. En los grupos grandes, los más activos son la introyección, la proyección, la identificación, la identificación proyectiva y la introyectiva, la escisión y la disociación. Cierto es que también están presentes la intelectualización, la racionalización; pero creo que los primeros son más básicos mientras que los segundos tratan de frenar las consecuencias de los primeros.

Coincido con Foulkes (1975), Main, T (1975) y con Turquet (1975) cuando refieren la aparición de mecanismos psicóticos en estos espacios grupales - lo que indica que la situación es vivida como peligrosa-. Las vivencias de fragmentación e invisibilidad (Turquet, 1975) pueden incrementar los niveles de confusión. Si no aparece una contención y se paraliza la capacidad de pensar, la emergencia de las identificaciones proyectiva e introyectiva torna caótica la situación.

La creación de un espacio en el que el reconocimiento del otro sea una realidad requiere tiempo y confianza en la conducción en el grupo. Ello permite pasar del poder estar al poder sentir; de ahí al poder pensar y finalmente poder hablar ${ }^{3}$. Este proceso, variable para cada uno, aporta importantes dosis de seguridad en la permanencia del Yo que no siempre uno siente que le están garantizadas.

Sabemos que la devolución de la imagen por parte del Otro refuerza los lazos vinculantes en tanto que se mantienen los vínculos narcisistas con el grupo y sus integrantes; fundamentalmente los que intervienen en el contrato narcisista secundario (Kaës, R, 2009). 
Muy probablemente, las vivencias de invisibilidad y de soledad señaladas por Turquet (1975) estén relacionadas con las dudas de su persistencia.

Ahora bien —segunda pregunta-, ¿cómo no daban fruto nuestros intentos por encauzar el pensamiento hacia lo creativo? Lo que nos lleva a pensar en el papel del conductor.

\section{El conductor y su conducción}

A muchos les puede sorprender que utilicemos la palabra conductor en vez de llamarlo terapeuta o psicoterapeuta de grupo.

Cuando Foulkes la introdujo pensaba en una orquesta. La voz inglesa conductor - que ha quedado traducida a nuestro idioma tal como suena, conductor - se correspondería a la de director; sólo que en español ésta tiene otras connotaciones que desaconsejan utilizarla.

¿Por qué un director de orquesta? Porque es el responsable de conseguir que cada músico saque lo mejor de sí mismo en la interpretación de la partitura, para que el conjunto suene como debe sonar. Los profesores aportan toda su técnica y conocimiento para que el director obtenga el resultado que busca. Él no es quien toca los instrumentos. Es quien se esfuerza para conseguir la atmósfera, el clima emocional y el estilo relacional para que la sinfonía suene de una determinada manera.

Tal es el sentido del conductor de un grupo. Su objetivo es conseguir un ambiente suficientemente facilitador para que cada uno aporte todo lo posible para el desarrollo normológico de todos. Esto marca una importante diferencia entre los posicionamientos más clásicos de la psicoterapia de grupo y el grupoanálisis -al menos tal como lo entiendo, más radical en el sentido de lo relacional-.

Los estilos de conducción dependen, en buena medida, de las características y experiencias del profesional. Pero también de los referentes conceptuales sobre los que construye su estilo; que en mi caso, evolucionó desde posiciones muy kleinianas —incluso lacanianas-a otras que, siendo radical (Dalal,2002), ponen el acento en lo relacional (Mitchell, 1993). Posiblemente el abanico abarque desde un extremo en el que el conductor se dirige al grupo sin sentirse plenamente parte de él (lo que sería la posición de Bion, 1976), a otra en la que forma parte del grupo (a pesar de una serie de responsabilidades que lo diferencian) en lo que pudiera ser una posición cercana a T. Burrow (Gati Pertegato, 2013). Un posicionamiento y su opuesto están representados en Foulkes como muy bien nos mostró Dalal.

Cuando el objetivo del profesional pone el en la construcción de unas relaciones higienizantes —estamos en la función conductora (Sunyer, 2008) - lo que busca es que todos 
quienes constituyen el grupo (incluido él mismo) puedan hablar de lo que quieran en una atmósfera de confianza y fiabilidad; a modo de madre suficientemente buena que permita el juego interactivo para potenciar su desarrollo (Winnicott, 1981, 1971). En consecuencia, la «libre discusión flotante» - paralela a la «libre asociación» del espacio psicoanalítico- se convierte en el terreno para la elaboración de los objetos internos con los que nos constituimos (Sunyer, 2002). Eso que parece muy genérico, no lo es tanto.

En algún lugar aprendí (Hopper, 2003) un esquema que me pareció muy clarificador. Atañe a las coordenadas lugar y tiempo en el que transcurren las conversaciones grupales:

\begin{tabular}{|l|l|l|}
\hline & Aquí & Allí \\
\hline Ahora & & \\
\hline Entonces & & \\
\hline
\end{tabular}

Lo que se espera, lo ideal, es que el grupo centre su trabajo en el aquí y ahora. Porque ser el terreno de juego común. Ahí todos conocemos las variables que se dan respecto a lo que nos ocurre. Sin embargo, se tiende a ubicar el núcleo de la conversación en cualquiera de las otras casillas. Es más fácil; pero oculta una realidad: la de centrar la atención a lo que ocurre en el momento presente; que es donde se ubica el o los problemas de quienes constituyen el grupo. $Y$ es un problema también para la conducción. ¿Dónde se coloca el conductor o conductores?

Al pensar en la historia de la individualidad de cada miembro del grupo tendemos a valorar los relatos en tanto que aportan pistas, claves que explican o aclaran su situación individual. Pero considerando el aquí y ahora, estos relatos no dejan de ser movimientos relacionales que buscan alejarnos de los vínculos que establecemos con los demás miembros del grupo. Son, en realidad, el reflejo metafórico de cosas que están sucediendo en el aquí y ahora grupal. Tengan que ver con historias pasadas de los componentes del grupo o relatos que guarden relación con lo social: todo ello alude a aspectos de la relación, a las dificultades que tenemos en el encuentro real con el otro. Como bien dice el refrán, cuando Pablo habla de Pedro, habla más de Pablo que de Pedro.

¿Y en nuestro caso? 


\section{La contaminación del objeto de estudio: una lectura de la sesión.}

Las características de las personas que forman un grupo así como los objetivos que se buscan condiciona las relaciones que se establecen. A esto lo llamé contaminación del objeto de estudio que no es más que la consecuencia de desarrollar unas relaciones entre los miembros del grupo en las que se inoculan las dificultades o características comunes de sus integrantes y las de la institución que les da cobijo (Sunyer, 1997, 2008) y que en cierto modo rememora lo señalado por Nitsun en cuanto al espejo organizativo (Nitsun 1998a, b).

En nuestro caso, todos los grupos y actividades venían bajo un lema: Las lenguas de los Grupos: el poder de incluir y excluir. Esto significa que la inclusión y la exclusión van a estar presentes en todas las actividades que se realicen. ¿Cómo apareció en el GG?

Nada más iniciar el segundo encuentro aparecieron comentarios sobre verse o no incluidos, lo que en cierto modo activó en mucho el fantasma que señorea por el encuentro y que atañe a quienes estamos en él. Fundamentalmente la inclusión o exclusión: un error en la comunicación del presidente del Simposio - no mencionar la presencia de personas de un país concreto- encendió la mecha de la exclusión.

Es básico sentirse incluido. Y más en un grupo grande en el que cualquier fallo en la comunicación adquiere dimensiones proporcionadas al número de espejos que hay en esta sala. Si la identidad es esa imagen - y la conciencia que se deriva - que se construye a partir de las relaciones con uno mismo, y con todo lo que le rodea y constituye su existencia, cuando una persona se ve inmersa en un grupo grande, uno de sus temores es el mantenimiento de su identidad.

Aquel olvido por parte de un responsable del Simposio fue vivido por una persona como un no reconocimiento de su identidad nacional. Momento en el que se agitó la carpa (Volkan, 2018) sostenedora de la identidad colectiva de cada miembro del grupo. En realidad, nuestro encuentro virtual es también una amenaza a la identidad individual: no somos lo que éramos. Algo relacionado con la reivindicación ideológica (Volkan, 2018) se convierte en parte de la identidad individual y colectiva. En este sentido cuando alguien siente -o interpreta- que su exclusión equivale a un no reconocimiento de su identidad personal y colectiva, reacciona. Lo virtual, juntándonos, nos separa. ¿Dónde queda nuestra identidad?

En este momento y ante la fragilidad que se vive al estar inmerso en un grupo virtual, se inicia un encadenamiento de identificaciones con la fragilidad de otros miembros del grupo. En unos casos, reivindicando también su reconocimiento como representantes de su identidad nacional o étnica. En otros, identificándose con la persona dañada, se solidarizan a través de esa misma identificación: a ellos también se les ha dañado. Al mismo tiempo, unos terceros 
se solidarizan con otra parte del grupo entrando, inmediatamente a formar parte de esa asociación encadenada de agravios y no reconocimientos compartidos.

Cuando esto sucede, la reacción de las personas confirma el daño sufrido; y al vivirse con tal multiplicidad, no son suficientes ninguna de las razones que se puedan argumentar para disminuir el intenso escozor de la herida. Al entrar en este círculo es fácil que muchos se identifiquen con el dolor de la persona que se siente discriminada, sintiéndose a su vez discriminados o con la posibilidad de serlo. En estos momentos uno no se siente sujeto pensante sino representante de una lengua, de una etnia, de una religión o de una ideología. Ya no es un sujeto en relación a otros sujetos. El grupo parece que se convierte en una reunión de representantes de las lenguas, de las etnias, de los territorios, de las razas. Uno, su identidad, se ha reducido a lo que «representa» y no a lo que es. Se hace difícil recuperar las capacidades de pensar, de poner pensamientos que permitan reconducir los sentimientos y faciliten que el grupo, ese espacio mental de elaboración de objetos internos, vaya a por su objetivo y razón de ser. La emoción supera la razón. Y es ahí, por donde penetra la confusión en el grupo que ha quedado contaminado por el objeto de estudio, esto es, por la razón por la que estamos juntos.

A toda esta realidad hay que sumarle otra: la virtualidad.

En efecto, la enorme diferencia con otros grupos grandes ha sido su formato virtual. Es imposible tener en pantalla a los casi 300 participantes, por lo que el individuo y su visibilidad quedan muy dañados. A la pérdida de la información que proviene del lenguaje corporal solo se veía, como mucho, la cara del hablante- se le añadía una distorsión importantísima de su voz. Si se atendía a la traducción simultánea - recordemos que el congreso era trilingüe- a la profesional que realizaba esa labor le resultaba casi imposible transmitir el tono, sus variaciones modulares, sus matices, el ritmo verbal del hablante, por lo que la impresión que se transmitía era más bien negativa: pérdida de identidad. Si se hacía caso a la voz directa del hablante, no todo el mundo dominaba las otras dos lenguas por lo que muchos aspectos se perdian también: aislamiento. A ello hay que añadir el elemento espacial que, aún estando en la misma pantalla, en realidad cada uno estaba en su casa (su castillo), exclusión.

Lo virtual excluye lo real.

\section{La conducción}


En este escenario también estaba la conducción -al menos la que me corresponde-. Ahí reconozco haber detectado al segundo el momento en el que la confusión se introdujo y comenzó a arraigar.

Quise intervenir pero aparecieron dos dudas:

a) ¿Era ese el estilo GASI? Lo desconocía; lo que no pretende ser una excusa. No dejaba de ser un extranjero en esa tierra. Como cuando le invitan a comer a una casa por primera vez y no sabe las reglas o normas que rigen su dinámica; por ejemplo, en dónde se sienta cada cual. ¿Exclusión o no inclusión?

b) Si intervenía como creía — silenciando todas las voces para hacerme oír- igual me acusan de prohibir el libre desarrollo del pensamiento de este grupo.

Reconozco que tuve segundos de duda y que, cuando intervine, sentía que mi voz no llegaba - ia ver, un momento!, iba repitiendo una y otra vez-, como si en cierta forma quedara excluido del grupo por no pertenecer a la cultura dominante (GASI).

Cuando me rehíce entré en pánico: mi imagen había desaparecido de la pantalla y mi voz no llegaba a los oídos de los del grupo. Fueron segundos, lo sé; hasta que el servicio técnico me introdujo de nuevo en la sesión. Alguien dijo ¡el conductor no está, no tenemos conductor!, lo que agravó el nivel de ansiedad colectiva.

Ciertamente resultaba difícil —casi imposible - que la voz de cualquiera de mis compañeros de conducción llegara a los miembros como «algo está diciendo el conductor». Los traductores no podían poner nuestra propia voz, nuestro propio estilo. Nuestras voces, las de los intérpretes, la del resto de los miembros del grupo se entremezclaron en un torbellino enloquecedor. Tuvimos que acudir a silenciar todos los micrófonos para posibilitar que fuese oída nuestra voz.

Ese aspecto técnico ¿qué generó? La vivencia de que no tenemos quien nos conduzca. $Y$ de ahí al caos o a la confusión, va un paso. La exclusión tomó plaza activándose lo que en términos de Bion sería el supuesto de ataque-fuga; que en nuestra terminología se denomina confusión y agresividad grupal.

Ahora, la tercera pregunta: por qué un grupo grande tiende o incluye la confusión en su dinámica y cómo se introduce y se sale de ella? 


\section{Vías de penetración de la confusión.}

Cinco son las funciones suficientes y necesarias para organizar cualquier grupo: la función convocante, la vinculante, la higiénica, la verbalizante y la teorizante (Sunyer 2008). Habrá que pensar que posiblemente la penetración de la confusión se realiza a través de ellas.

La función (Bion,1987) convocante acoge el conjunto de aspectos que guardan relación con la propia convocatoria: a quién, cuándo, dónde, cómo y porqué se invita a participar de una experiencia grupal. Aquí tal función la realizó la propia organización quien decidía quienes éramos los conductores; y aunque quienes lo fuimos — con dos sustituciones al cambiar de formato- aceptamos este encargo y nos reunimos previamente (e incluso fuimos supervisados por M. Nitsun), el convocado acude por invitación de la organización. Esto introduce un enlace débil entre quienes asisten y quienes se responsabilizan de acompañarles en estos encuentros. Los conductores a penas nos conocíamos (más Sue y Elisabeth entre sí) y la necesaria complicidad requerida no podía acabar de darse - por no añadir las dificultades idiomáticas-. Esas grietas (posiblemente inevitables dadas las circunstancias) pudieron favorecer la aparición de la confusión.

La función vinculante. El grupo fue virtual —significa, falso- lo que influyó ciertamente. Porque estando todos en la misma pantalla, estábamos cada uno en nuestro castillo. Cierto que no había alternativa; pero el vínculo que se establece no es el mismo. Desaparece la mayor parte del lenguaje corporal, la voz se modifica (añadiéndole las voces correspondientes a los traductores para quienes es imposible hacer más que su labor) y, sobre todo es imposible o muy difícil captar la dinámica de lenguajes corporales del grupo en general. Entiendo la fascinación que genera en muchos tal medio, pero al tiempo es una amenaza a la relación interpersonal.

La función higiénica atañe a las normas y al marco de nuestra relación. Y aunque están bien interiorizadas en todos -o la mayoría - de los participantes, la estructura de la propia convocatoria era compleja. Silenciar al grupo en general para evitar el ruido de fondo, acompasar unos comentarios con otros, ver cómo se sentía cada uno con el medio. No se dio tiempo para considerar la virtualidad del encuentro, sus pros y contras, lo cómodos o incómodos que podíamos estar. Incluir también los elementos administrativos y económicos del congreso, el desarrollo de las diversas actividades, etc.; de todo esto no se habló. Al no revisar los aspectos estructurales del aquí y ahora, todas las quejas que pudieran haber quedaron excluidas de la relación.

Fue difícil de establecer la función verbalizante. La presencia de abundantes identificaciones proyectivas e introyectivas acabaron paralizando la capacidad de pensar; desbordada por las emociones desatadas. Involuntariamente también, la presencia de los traductores añadía 
más ruido añadiéndosele que, inevitablemente, desaparecía buena parte de la entonación y emoción originales. Cuando la función yoica grupal no puede estructurarse, ésta debe ser retomada por los conductores; pero en nuestro segundo encuentro, la complejidad técnica dificultó y casi impidió que pudieran asumirla. Eso facilita la victoria de la confusión y, por ende, la descomposición del grupo.

Un elemento añadió complejidad a dicha función: la co-conducción -tres conductoresrequiere no solo la coordinación de las intervenciones sino, y sobre todo, la concordancia en la comprensión de los fenómenos observados. Ello conlleva un trabajo previo de conocerse lo suficiente como para crear el «equipo necesario» que, aún diciendo cosas diversas, no difieran en la dirección. $Y$ un mismo lenguaje. No solo en cuanto al idioma sino $-\mathrm{y}$ sobre todo- a los referentes emocionales e intelectuales. Ciertamente hicimos el esfuerzo previo para constituirnos como equipo, incluso mediante la ayuda de Morris Nitsun como supervisor de los tres; sin embargo, a las diferencias idiomáticas se sumaban posiblemente otras de tipo técnico e incluso de filosofía de la conducción.

La quinta función, la conceptual, es la que se realiza a través de esas líneas. Es de suponer que al no poderse desarrollar plenamente cuatro de las cinco funciones, la confusión -eso es, las fuerzas destructoras- se apoderan del grupo. Pero eso lo abordaré en otro trabajo.

\section{Conclusión.}

Creo que es importante valorar las cinco funciones que, siguiendo a Bion, nos permiten desarrollar la capacidad de pensar sobre lo que sucede en un grupo cualquiera. El establecimiento del equipo de conductores debe seguir más la metáfora de ir en tándem que la de ir en bicicletas (Sunyer, 2016) dado que el equipo de trabajo debe poder trabajar en equipo (Sunyer, 1997).

Con todo, es cierto que la experiencia de los tres grupos acabó bien. La gente agradeció los encuentros y volvieron a emerger los comentarios afectuosos del primer día. $Y$ a pesar de que muchos de nosotros vivimos una situación compleja en el segundo encuentro, la despedida fue agradable. Parce claro que se precisa elaborar lo sucedido. Y en parte, este ha sido el resultado.

\section{REFERENCIAS}

Bion, W. R. (1976). Experiencias en grupo. Buenos Aires: Paidos.

- (1987). Aprendiendo de la experiencia, $1^{\text {a }}$ Reimpresión. Buenos Aires: Paidós. 
Dalal, F. (2002). Taking the Group Seriously, London, Constable.

de Maré, P. (2010). Textos escogidos. Barcelona Cegaop Press

de Maré, P., Piper, R., Thompson, S. (1991). Koinonia. From Hate, through Dialoge, to Culture in the Large groups. Londres: Karnac Books

Foulkes, S.H. (1975). Problems of the large group from a group-analytic point of view. En Kreeger, L. (1975) (Ed). The large Group. Londres: Constable.

Gatti Pertegato, E.; Pertegato, G. O. (2013). From Psychoanalysis to Group Analysis. The pioneering work of Trigant Burrow. London: Karnac

Hopper, E. (2003). The Social Unconscious. Selected papers. Londres, JPK

Kaës, R, (2009). Les alliances inconscientes. París: Dunod

Main, T. (1975). Some psychodinamics of large group. En Kreeger, L. (1975) (Ed). The large Group. Londres: Constable

Mitchell, S.A. (1993). Conceptos relacionales en psicoanálisis. Una integración. México: S. XXI

Nitsun, M. (1998a). The Organizational Mirror: A Group-Analytic Approach to Organizational Consultancy, Part I. Group Analysis 31 (3): 245-267

-. (1998b). The Organizational Mirror: A Group-Analytic Approach to Organizational Consultancy, Part II. Group Analysis 31 (4): 505-518

Sunyer, J.M. (1996). Una experiencia grupoanalítica en el marco de la enseñanza universitaria. Clínica y análisis grupal 18(3):379-95

- (1997). Del equipo de trabajo al trabajo en equipo. En J.M Sunyer (2018). Escritos grupoanalíticos. Todo un tiempo aprendiendo. Madrid: vivelibro

- (1998). El grupo grande. Desarrollo histórico y psicoterapéutico. Boletín 11:3-21

- (1998a). Algunos aspectos de la contratransferencia en una experiencia grupoanalitica universitaria

- (2001). La confusión en el grupo grande. Boletín. 22:3-14

- (2002). El grupo: espacio mental de elaboración de los procesos de integración y diferenciación de los elementos biospciosociales del ser humano. En J.M. Sunyer (comp) Escritos grupoanalíticos. Todo un tiempo aprendiendo. Madrid: VieLibro

- (2008). Psicoterapia de grupo grupoanalítica. El proceso de coconstrucción de un conductor de grupos. Madrid: Biblioteca Nueva

- (2016). Bicicletas o Tándems. En J.M Sunyer (2018). Escritos grupoanalíticos. Todo un tiempo aprendiendo. Madrid: vivelibro

Turquet, P. (1975). Threats of Identity in the large group. En Kreeger, L. (1975) (Ed). The large Group. Londres: Constable

Volkan, V. (2013). La identidad del grupo grande y el prejuicio compartido. Teoría y práctica grupoanalítica. 3(1):29-44 
- (2013b). Psicología de las sociedades en conflicto. Barcelona: Iniciativas grupales. Hay una nueva edición publicada por Herder en 2918.

- (2004). Blind trust. Large groups and their Leaders in Times of Crisis and Terror, Virginia, Pitchstone Publ.

- (2006). Killing in the name of identity, Virginia, Pitchstone

- (2013a). Enemies on the Couch.A psychological journey trheugh ward and peace. Virginia, Pitchstone.

Winnicott, D.W. (1971). Realidad y juego. Barcelona: Gedisa

- (1981). Preocupación maternal primaria. En Winnicott. D. W, (1981), Escritos de pediatría y psicoanálisis, Barcelona, Laia.

Original recibido con fecha: 9/10/2020 Revisado: 17/11/2020 Aceptado: 30/03/2021 NOTAS:

${ }^{1}$ Máster en Psicoterapia Analítica Grupal. Universidad de Deusto-Fundación OMIE

${ }^{2}$ He vivido varias situaciones de GG en la que uno de los integrantes ha precisado atención profesional con posterioridad al grupo, recomendándole en algún caso, algo de medicación.

3 Estas cuatro fases fueron descritas aunque nunca publicadas por J.Ma Ayerra. 